\title{
Korean Elementary School Students' Playtime, School Life Satisfaction and Child Happiness
}

\author{
E-Rang Kwak \\ HanSin Elementary School \\ Seoul, Korea/ Teacher
}

\begin{abstract}
The purpose of the study is to reveal the relationship between Korean elementary school students' playtime, school life satisfaction and child happiness. Elementary school students in Korea are spending more and more time at school as after-school classes are activated, and play and rest times are decreasing. Play and rest are essential factors for the development and learning of students in childhood, and the UNICEF specified the Convention on the Rights of the Child. Gradually, the critical competences of $21 \mathrm{C}$ - Creativity, Critical Thinking and Communication can be experienced and developed by playing. Therefore, this study conducted correlation and regression analysis on 801 elementary school students in Korea by examining play time, school life satisfaction, and happiness in order to show the importance of play and rest time. According to the analysis, play and rest times were significantly correlated with school life satisfaction, and physical and cognitive play activities had a static effect on school life satisfaction. Second, play and rest have a significant correlation with happiness, and physical and emotional play activities have had a static effect on happiness. Based on the results of this study, I would like to say that elementary school students need to be guaranteed playing time during school work and that efforts are needed to support students' play and rest. School activities are obliged to find what they can do for the healthy development of students. Since it is essential for students to adjust to school life, be satisfied, and feel happy, they should be fully supported through play and rest times in school.
\end{abstract}

Keywords: childhood; development; education; playing; school 